\title{
Anorectal diseases in patients with Antiphospholipid syndrome: a cross- sectional study
}

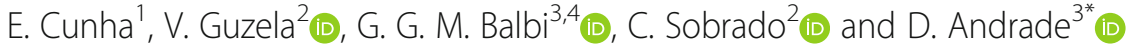

\begin{abstract}
Background: Hemorrhoid disease (HD) is one of the most common gastrointestinal complaints worldwide, affecting $4.4 \%$ of the general population in the United States. Since antiphospholipid syndrome (APS) may lead to intra-abdominal thrombosis, one may expect that this condition can impact the risk for HD development. Additionally, as APS patients are more prone to thrombosis and treatment with anticoagulants may increase risk of bleeding, one may also infer that rates of HD complications may be higher in this scenario. Nevertheless, no data in these regards have been published until now. The objective of the present study is to evaluate frequency of HD and describe its complications rates in antiphospholipid syndrome APS patients.

Methods: We consecutively invited patients who fulfilled APS criteria to undergo proctological examination. After examination, patients were divided in two groups, based on the presence of HD, and compared regarding different clinical manifestations and antiphospholipid profile. We performed the analysis of the data, using chi-square and Mann Whitney $U$ when applicable and considering a significance level of 0.05 . Multivariate regression analysis included age and variables with $p<0.10$ in the bivariate analysis.
\end{abstract}

Results: Forty-one APS patients agreed to undergo proctological examination. All were female and overall median age was 43 (36-49). Seventeen (41.4\%) patients were diagnosed with HD, with the following frequency distribution: 7 internal (41.2\%), 4 external (23.5\%) and 5 mixed hemorrhoids (29.4\%). Of the internal hemorrhoids, 5 patients were classified as grade I (71.4\%), 1 grade II (14.3\%), and 1 grade IV (14.3\%). Prior gestation $(p=0.067)$ and constipation ( $p=0.067)$ correlated with a higher frequency of HD. In multivariate analysis, constipation remained as an important risk factor (OR 3.92,C195\% 1.03-14.2,p=0.037). Five out of 17 patients (29.4\%) reported anal bleeding, but it did not correlate with warfarin dose $(p=0.949)$. Surgical treatment was indicated for 10 patients $(58.8 \%)$. Other anorectal findings were anal fissure, plicoma, condyloma and one chlamydial retitis.

Conclusion: We found an unexpected high frequency of hemorrhoids in APS patients, with a great proportion requiring surgical treatment.

Keywords: Antiphospholipid syndrome, Antiphospholipid antibodies, Rectal diseases, Anus diseases, Hemorrhoids, Hemorrhoidal disease

\footnotetext{
* Correspondence: danieli.andrade@hc.fm.usp.br

${ }^{3}$ Discipline of Rheumatology, Hospital das Clínicas/Faculdade de Medicina (HC-FMUSP), University of São Paulo, Av. Dr. Arnaldo 455, Third Floor, Room 3109, São Paulo 01246903, Brazil

Full list of author information is available at the end of the article
}

(c) The Author(s). 2020 Open Access This article is licensed under a Creative Commons Attribution 4.0 International License, which permits use, sharing, adaptation, distribution and reproduction in any medium or format, as long as you give appropriate credit to the original author(s) and the source, provide a link to the Creative Commons licence, and indicate if changes were made. The images or other third party material in this article are included in the article's Creative Commons licence, unless indicated otherwise in a credit line to the material. If material is not included in the article's Creative Commons licence and your intended use is not permitted by statutory regulation or exceeds the permitted use, you will need to obtain permission directly from the copyright holder. To view a copy of this licence, visit http://creativecommons.org/licenses/by/4.0/. 


\section{Background}

Antiphospholipid syndrome (APS) is characterized by thrombosis and/or pregnancy morbidity, such as recurrent abortions, fetal loss and preterm birth, in the presence of antiphospholipid antibodies. Laboratory diagnosis is based on the persistent detection of lupus anticoagulant (LA), IgM or IgG anticardiolipin antibodies $(\mathrm{aCL})$ in moderate to high titers and/or IgM or IgG anti- $\beta 2$-glycoprotein I antibodies (aß2GPI) in titers over the 99th percentile [1].

Hemorrhoid disease (HD) is one of the most common gastrointestinal complaints worldwide, affecting $4.4 \%$ of the population in the United States. Its peak of incidence ranges from age 45 to 65 years, for both genders [2]. Anorectal symptoms may include bleeding, pain, prolapse, itching and/or soiling [3]. The most common complications of HD are thrombosis (especially in external hemorrhoids) and bleeding (especially in internal hemorrhoids) [2].

Hemorroids are characterized according to its origin relative to the dentate line, as: (1) internal (if proximal to this line), (2) external (if distal to this line), and (3) mixed (if both complexes are involved). Internal hemorrhoids can be further graded into four different stages (Goligher classification): grade I (1st degree or primary hemorrhoids) - prominent and engorged vasculature, no prolapse; grade II (2nd degree or secondary hemorrhoids) - prolapses with straining, spontaneous reduction; grade III (3rd degree or tertiary hemorrhoids) prolapses beyond dentate line with straining and can only be reduced with manual maneuvers; and grade IV (4th degree or quaternary hemorrhoids) - evident prolapsed tissue, not reducible $[3,4]$.

There are several reported risk factors for the development of HD, including constipation, prolonged and/or frequent straining, obesity, increased intra-abdominal pressure, cirrhosis with ascites and pregnancy, all of them concurring to increase venous pressure and impair venous drainage [4]. Since APS may lead to intraabdominal thrombosis, one may expect that this condition can impact the risk for HD development. Additionally, as APS patients are more prone to thrombosis and treatment with anticoagulants may increase risk of bleeding, one may also infer that rates of HD complications may be higher in this scenario. Nevertheless, no data in these regards have been published until now.

The primary objective of this study was to evaluate the frequency of HD and describe rates of HD complications in APS patients. We also recorded other anorectal diseases as an exploratory objective.

\section{Methods}

This is a cross-sectional study of HD and other anorectal diseases in APS patients. We consecutively invited patients who fulfilled Sydney criteria [1] and were frequently seen in our APS outpatient clinics to undergo proctological examination by an experienced colorectal surgeon. Anorectal symptoms were recorded only if they had a moderate to high frequency. Constipation was classified according to the Rome IV criteria. Clinical and serological data were obtained during visits and by chart review.

After examination, APS patients were divided in two groups, based on the presence of HD, and compared regarding different clinical manifestations and antiphospholipid profile.

We performed the analysis of the data, using chisquare and Mann Whitney $U$ when applicable and considering a significance level of 0.05 . Multivariate regression analysis included age and variables with $p<0.10$ in the bivariate analysis.

This study was approved by the Ethics Committee of our institution (\#2.368.484) and patients signed written informed consent, which have been archived in the Rheumatology department.

\section{Results}

Ninety-one APS patients were consecutively invited and $41(45 \%)$ agreed to undergo proctological examination. Of those, all were female and overall median age was 43 (36-49). The most common causes for refusal to participate were: (1) patient considered proctological examination uncomfortable; and (2) absence of anal complaints.

Seventeen $(41.4 \%)$ patients were diagnosed with HD, with the following frequency distribution: 7 had internal (41.2\%), 4 external (23.5\%) and 5 mixed hemorrhoids (29.4\%). Of the internal hemorrhoids, 5 patients were further classified as grade I (71.4\%), 1 as grade II (14.3\%), 1 as grade IV (14.3\%).

Patients diagnosed with HD were slightly older than those without HD (median 49 [39-53] vs. 41.5 [33.25$45]$ ), even though this difference did not reach statistical significance.

Women with prior gestation $(p=0.067)$ and those with constipation $(p=0.067)$ showed a tendency for higher frequency of $\mathrm{HD}$. In a multivariate analysis, constipation remained as an important risk factor (OR 3.92, CI95\% $1.03-14.2, p=0.037$ ). Obesity, family history of HD, previous history of arterial or venous thrombosis, presence of lupus anticoagulant, anticardiolipin, anti-ß32-glycoprotein or triple positivity were not associated with a higher frequency of HD.

In the HD group, the most frequently reported signs were prolapse during defecation (88.2\%), increased evacuation effort (64.7\%) and anal discomfort (47.1\%).

Regarding hemorrhagic complications of hemorrhoids, 5 out of 17 patients (29.4\%) reported anal bleeding. Only two of all HD patients were not taking warfarin at the 
time of data collection; of those, one presented anal bleeding and the other did not. Anal bleeding did not correlate with warfarin dose in patients with $\operatorname{HD}(p=$ 0.949). No episode of thrombosed hemorrhoids was reported during proctological examination.

Surgical treatment was indicated for 10 patients (58.8\%), due to internal hemorrhoid grade III or IV, mixed or external hemorrhoids.

Clinical and laboratory characteristics of each group are summarized and compared in Table 1.

Other anorectal findings were anal fissure $(N=5$, $12.2 \%)$, plicoma $(N=16,39 \%)$, condyloma $(N=2,4.9 \%)$ and one chlamydial retitis $(\mathrm{N}=1,2.4 \%)$. Of the 2 condyloma patients, one was taking mycophenolate mofetil 500 mg BID and the other was on mycophenolate mofetil $1500 \mathrm{mg}$ BID. The patient with chlamydial retitis was using azathioprine $100 \mathrm{mg}$ QD and prednisone $30 \mathrm{mg}$ QD.

\section{Discussion}

To the best of our knowledge, this is the first study about HD and other anorectal diseases in APS patients.
We found an unexpected high frequency of hemorrhoids (41.4\%) in APS patients, if compared to the results of the largest published study in general population (prevalence of 4.4\%) $[2,5]$.

Additionally, our patients were relatively young (median 43, interquartile range 36-49), when compared to peak incidence of HD (45-65 years) [2], what may suggest patients with APS are prone to develop HD earlier in life. Even though we cannot confirm this supposition without further prospective studies and matched healthy controls, the median age of our patients diagnosed with HD was 49 (interquartile range 39-53) and we did not find differences between ages of patients with or without HD in our sample.

Furthermore, $58.8 \%$ of our patients were referred to surgical treatment due to internal hemorrhoid grade III or IV, mixed or external hemorrhoids, suggesting that APS patients may have a more severe presentation of $\mathrm{HD}$ at the beginning and may require surgical interventions more often.

In our cohort, we identified that constipation correlated with a higher risk of $\mathrm{HD}$, resembling the existing

Table 1 Clinical and laboratory characteristics of APS patients included, according to HD diagnosis

\begin{tabular}{|c|c|c|c|}
\hline & Hemorrhoidal Disease $(N=17)$ & No Hemorrhoidal Disease $(N=24)$ & $p$-value \\
\hline \multicolumn{4}{|l|}{ Demographic characteristics } \\
\hline Female gender $(\mathrm{N}, \%)$ & $17(100 \%)$ & $24(100 \%)$ & - \\
\hline Age (Median, IQR) & $49(39-53)$ & $41.5(33.25-45)$ & 0.09 \\
\hline \multicolumn{4}{|l|}{ Risk factors possibly related to HD } \\
\hline Body Mass Index (Median, IQR) & $29.9(25.8-35.2)$ & $28.57(25.14-30.99)$ & 0.223 \\
\hline Obesity (N, \%) & $8(47.1 \%)$ & $7(29.2 \%)$ & 0.241 \\
\hline Pregnancy (ever; N,\%) & $15(88.2 \%)$ & $15(62.5 \%)$ & 0.067 \\
\hline Constipation $(\mathrm{N}, \%)$ & $9(52.9 \%)$ & $6(25 \%)$ & 0.067 \\
\hline Family history of $\mathrm{HD}(\mathrm{N}, \%)$ & $8(47.1 \%)$ & $7(29.2 \%)$ & 0.241 \\
\hline \multicolumn{4}{|l|}{ APS clinical and serological characteristics } \\
\hline Arterial thrombosis $(\mathrm{N}, \%)$ & $7(41.2 \%)$ & $8(33.3 \%)$ & 0.607 \\
\hline Venous thrombosis $(\mathrm{N}, \%)$ & $11(64.7 \%)$ & $16(66.7 \%)$ & 0.896 \\
\hline Lupus anticoagulant $(\mathrm{N}, \%)$ & $13(76.5 \%)$ & $14(58.3 \%)$ & 0.130 \\
\hline Anticardiolipin (N,\%) & $4(23.5 \%)$ & $3(12.5 \%)$ & 0.355 \\
\hline Anti-ß2-glycoprotein I $(\mathrm{N}, \%)$ & $5(71.4 \%)$ & $7(77.8 \%)$ & 0.771 \\
\hline Triple positivity (N,\%) & $1(5.9 \%)$ & $1(4.2 \%)$ & 0.715 \\
\hline \multicolumn{4}{|l|}{ Anorectal symptoms/signs } \\
\hline Rectal exteriorization during defecation & $15(88.2 \%)$ & $13(54.2 \%)$ & $0.021^{*}$ \\
\hline Increased evacuation effort & $11(64.7 \%)$ & $11(45.8 \%)$ & 0.233 \\
\hline Anal discomfort & $8(47.1 \%)$ & $4(16.7 \%)$ & $0.035^{*}$ \\
\hline Pain during defecation & $6(35.3 \%)$ & $9(37.5 \%)$ & 0.885 \\
\hline Anal burning & $6(35.3 \%)$ & $4(16.7 \%)$ & 0.171 \\
\hline Plicoma & $5(29.4 \%)$ & $11(45.8 \%)$ & 0.288 \\
\hline Bleeding & $5(29.4 \%)$ & $3(12.5 \%)$ & 0.178 \\
\hline Anal itching & $4(23.5 \%)$ & $5(20.8 \%)$ & 0.837 \\
\hline Anal Fissure & $1(5.9 \%)$ & $4(16.7 \%)$ & 0.299 \\
\hline
\end{tabular}

APS Antiphospholipid syndrome, HD Hemorrhoidal diseases, IQR Interquartile range. ${ }^{*} p<0.05$ 
literature about risk factors for HD in other subgroups of patients [6, 7]. Nevertheless, we could not demonstrate an association between obesity and HD, what is in disagreement with other previously published studies $[6$, 8].

The cornerstone of APS treatment is anticoagulation therapy with vitamin $\mathrm{K}$ antagonists (VKA) and this is another point that needs consideration when treating HD in APS patients. One can anticipate that VKA may increase the risk of anal bleeding in those with HD and may limit surgical therapeutic options, due to increased risk of postoperative hemorrhage.

Five of our patients with HD diagnosis (29.4\%) reported a past history of anal bleeding, but we were not able to check international normalized ratio (INR) of those using warfarin at the time of bleeding event. We tried to surpass this limitation using current dose of warfarin. However, we found no correlation between warfarin dose and history of anal bleeding.

Conservative measures are the mainstay treatment for HD in patients on anticoagulants [3]. A meta-analysis of 7 clinical trials comprising of 378 patients with hemorrhoids showed that fiber supplement had a consistent benefit of relieving symptom and minimizing risk of bleeding by approximately 50\% [9]. However, even this strategy requires attention in APS patients. The amount of fibers consumed daily must be taken into account when prescribing VKA, as many of them also contain high levels of vitamin $\mathrm{K}$. Therefore, increasing intake of fibers in diet can result in loss of efficacy of anticoagulant therapy indirectly. Patients should be instructed to consume constant doses of vitamin $\mathrm{K}$ and VKA dose should be adjusted to the level of vitamin $\mathrm{K}$ consumed daily [10].

Antithrombotic treatment has already been associated with increased risk of delayed hemorrhage after rubber band ligation (RBL) $[2,11]$. RBL is one of the alternatives for treating HD. If RBL or other inpatient surgical procedures are necessary, physicians should consider withdrawing anticoagulant before these interventions $[3,12]$. Since APS requires lifelong VKA use, heparin bridging is mandatory in this context [13]. Alternatively, some other technique may be preferred in this subset of patients, such as injection sclerotherapy or transanal hemorrhoidal dearterialization (THD), which have been described as safe in patients on anticoagulants $[14,15]$.

In addition to hemorrhoidal disease, the physician should be aware of other anorectal diseases, considering that anal fissure, condyloma and chlamydial retitis were found in our patient. As presented in the Results section, patients with condyloma and chlamydial retitis were using immunosuppression, which may have contributed to their occurrence.
Our study has several limitations. First, our sample is relatively small. Second, its cross-sectional design allows us only to suggest association, what needs to be confirmed in larger and prospective trials. Third, only 41 patients (45\%) agreed to undergo proctological examination and one of the main reasons for refusal was that they had no anal symptoms. This may have introduced a selection bias and may have led to a higher than expected frequency and/or severity of HD. Finally, we enrolled both primary and secondary APS and, thus, we cannot exclude SLE as a contributing factor for our findings. Nonetheless, our study also has strengths: it provides insights about a condition poorly studied in APS; proctological examinations were performed by an experienced staff from specialized outpatient clinics with high patient volumes; and we provided description of our anorectal findings (including others besides HD), what may help future research.

\section{Conclusions}

We found an unexpected high frequency of hemorrhoids in APS patients, with a great proportion requiring surgical treatment. Physicians who work with APS should actively ask their patients regarding anorectal disease and refer to a colon and rectal surgeon whenever necessary.

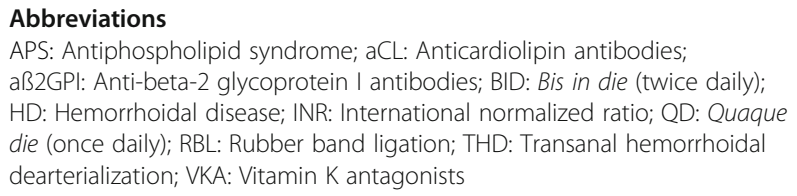

Acknowledgements

Not applicable.

\section{Authors' contributions}

$E C, G G M B$ and DA performed the clinical evaluation, and VG and CS performed the proctologic examinations of the patients. GGMB and DA analyzed the data and all authors contributed to the writing of the manuscript. The authors read and approved the final manuscript.

\section{Funding}

None.

Availability of data and materials

The datasets used and/or analyzed during the current study are available from the corresponding author on reasonable request.

\section{Ethics approval and consent to participate}

This study was approved by the Ethics Committee of the Hospital das Clínicas from University of São Paulo (approval \#2.368.484) and patients signed written informed consents, which have been archived in the Rheumatology department.

Consent for publication

Not applicable.

Competing interests

The authors declare that they have no competing interests. 


\section{Author details}

'Undergraduate student, Faculty of Medicine, University of São Paulo, São Paulo, SP, Brazil. 'Discipline of Colorectal Surgery, Hospital das Clínicas/ Faculdade de Medicina (HC-FMUSP), University of São Paulo, São Paulo, SP, Brazil. ${ }^{3}$ Discipline of Rheumatology, Hospital das Clínicas/Faculdade de Medicina (HC-FMUSP), University of São Paulo, Av. Dr. Arnaldo 455, Third Floor, Room 3109, São Paulo 01246903, Brazil. " Discipline of Rheumatology, Hospital Universitário, Federal University of Juiz de Fora, Juiz de Fora, MG, Brazil.

Received: 29 July 2020 Accepted: 25 September 2020 Published online: 07 October 2020

\section{References}

1. Miyakis S, Lockshin MD, Atsumi T, Derksen RHWM, Groot PGDE, Koike T International consensus statement on an update of the classification criteria for definite antiphospholipid syndrome. J Thromb Haemost. 2006;4(August 2005):295-306

2. Sun Z, Migaly J. Review of hemorrhoid disease: presentation and management. Clin Colon Rectal Surg. 2016;29:22-9.

3. van Tol R, Kleijnen J, Watson A, Jongen J, Altomare D, Qvist N, et al. European society of ColoProctology: guideline for haemorrhoidal disease. Colorectal Dis. 2020;22:650-62.

4. Jacobs D. Hemorrhoids. N Engl J Med. 2014;371:944-51.

5. Johanson J, Sonnenberg A. The prevalence of hemorrhoids and chronic constipation: an epidemiologic study. Gastroenterology. 1990;98:380-6.

6. Lohsiriwat V. Treatment of hemorrhoids: a coloproctologist's view. World J Gastroenterol. 2015;21:9245-52.

7. Lee J, Kim H, Kang J, Shin J, Song Y. Factors associated with hemorrhoids in Korean adults: Korean national health and nutrition examination survey. Korean J Fam Med. 2014;35:227-36

8. Loder P, Kamm M, Nicholls R, Phillips R. Haemorrhoids: pathology, pathophysiology and aetiology. Br J Surg. 1994;81:946-54.

9. Alonso-Coello P, Mills E, Heels-Ansdell D, López-Yarto M, Zhou Q, Johanson J, et al. Fiber for the treatment of hemorrhoids complications: a systematic review and meta-analysis. Am J Gastroenterol. 2006;101:181-8.

10. Klack K, de Carvalho JF. Dietetic issues in antiphospholipid syndrome. Rheumatol Int. 2013;33:823-4.

11. Nelson R, Thorson A. Risk of bleeding following hemorrhoidal banding in patients on antithrombotic therapy. Gastroenterol Clin Biol. 2009;33:463-5.

12. Lohsiriwat V. Hemorrhoids: from basic pathophysiology to clinical management. World J Gastroenterol. 2012;18:2009-17.

13. Saunders K, Erkan D, Lockshin M. Perioperative management of antiphospholipid antibody-positive patients. Curr Rheumatol Rep. 2014;16:426.

14. Yano T, Nogaki T, Asano M, Tanaka S, Kawakami K, Matsuda Y. Outcomes of case-matched injection sclerotherapy with a new agent for hemorrhoids in patients treated with or without blood thinners. Surg Today. 2013;43:854-8.

15. Atallah S, Maharaja G, Martin-Perez B, Burke J, Albert M, Larach S. Transanal hemorrhoidal dearterialization (THD): a safe procedure for the anticoagulated patient? Tech Coloproctol. 2016;20:461-6.

\section{Publisher's Note}

Springer Nature remains neutral with regard to jurisdictional claims in published maps and institutional affiliations.

Ready to submit your research? Choose BMC and benefit from:
- fast, convenient online submission
- thorough peer review by experienced researchers in your field
- rapid publication on acceptance
- support for research data, including large and complex data types
- gold Open Access which fosters wider collaboration and increased citations
- maximum visibility for your research: over 100M website views per year
At BMC, research is always in progress.
Learn more biomedcentral.com/submissions

